\title{
Just Short of
}

\section{Teleportation}

\section{Dear Reader,}

I suppose it was no coincidence that I couldn't help but recall the virtual world Second Life when I set out to draft this text. For those in need of a refresher: Second Life was developed by Linden Lab, and its introduction in 2007 was accompanied by a good deal of fanfare and hopeful anticipation on the part of prominent companies. At the time, the German newspaper Die Welt wrote: "In February, Daimler-Chrysler opened a virtual Mercedes Benz subsidiary in Second Life, where it also operates a test track for virtual test drives.” The article goes on to describe plans for successively expanding brand outreach, with competitors such as BMW, Toyota, Nissan, Mazda and GM also getting involved, and VW and the German Association of the Automotive Industry (VDA) following the development with great interest. In the end, not much came of the digital replica of the (business) world because the 2008/2009 crisis intervened. In the meantime, a lot of water has gone under the bridge - and we've seen a surge in computing power and bandwidth.

Our current situation has fueled expectations that activities will shift more extensively toward the virtual; essentially going the way of what has become an ever more digitized product development. Do I really need to fly to Mumbai for a meeting or to San Jose to attend Nvidia's GTC, or would it suffice to send an avatar, which would even allow me to meet colleagues for post-session talks? With the right tools, I could even participate on location - virtually, of course in hands-on sessions at the GTC, for instance, in the area of programming or debugging. In the case of meetings, it depends on the purpose, and whether we already know the people involved. While physical presence may be important when meeting people for the first time or when discussing the haptics of new in-vehicle materials, it's likely to be superfluous for a longstanding workgroup interested only in exchanging information.

Much will likely depend on the development of communication tools. In any case, the learning curve has been steep when it comes to the necessity of travel for less important meetings - and that with the rather spare possibilities of videoconferences, replete with splitscreen appearances. Yes, much work will need to be done to recreate the experience of sharing a post-meeting drink at the bar. On the other hand, my own online winetasting session, with wines from the Rheingau region, suggest that there's quite a bit of potential there even though I hesitated to join in when the first participants started singing.

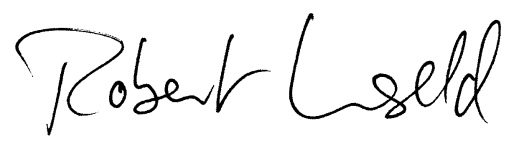

Robert Unseld

Responsible Editor

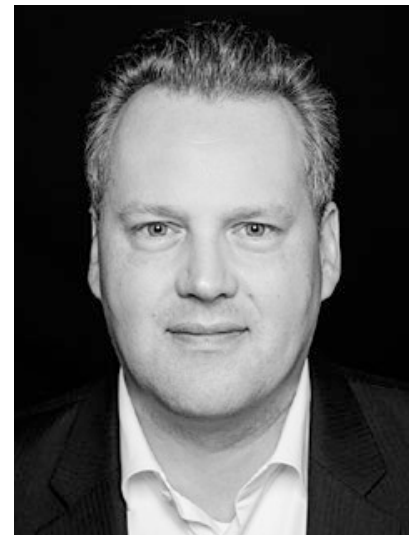

留

Unleash

the power onto the

road!

Together we take sensor technology to the next level. With your Al. And our servers.

In-vehicle server performance for automotive applications. With the DATALynx Product Line

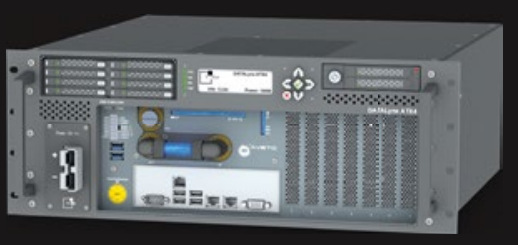

